\title{
Numerical Investigations of the Effect of Different Dust Outlet Designs on the Cyclone Performance and Flow Pattern
}

\author{
Kh. Elsayed ${ }^{*}$ and C. Lacor ${ }^{\dagger}$
}

\begin{abstract}
The effect of the cyclone dust outlet shape on the flow field pattern and velocity profiles has been investigated computationally using Reynolds stress turbulence model (RSM) for four cyclone separators (without dustbin, with dustbin, with dipleg, and with dust hopper (dipleg plus dustbin)). Results show that, the maximum tangential velocity is almost the same for the four tested cyclones. No acceleration occurs in the cyclone space (the maximum tangential velocity is nearly constant throughout the cyclone). Neglecting including the dustbin in the flow domain causes a slightly over estimation of the pressure drop. While a negligible under-estimation in the pressure drop is obtained when neglecting the effect of dipleg. The axial velocity profiles for the four cyclones are different. An inverted V profiles when including the dustbin and an inverted $\mathrm{W}$ profiles without the dustbin or with the dipleg. The differences between the pressure drop and cut-off diameters obtained with and without the dustbin or dipleg are minor. Consequently, the numerical simulations of cyclone separator without dustbin or dipleg are quite acceptable with large saving in computational resources.
\end{abstract}

Keywords: Cyclone separator, Cyclone geometry, Dustbin, Dipleg, Reynolds stress turbulence model (RSM)

\section{Introduction}

Cyclones are one of the most widely used separators, which rely on centrifugal forces to separate particles from a gas stream. The primary advantages are economy, simplicity in construction and adaptability to a wide range of operating conditions. Reversed flow cyclones with a tangential inlet are the most common cyclone design as shown in Fig. 1. It consists of seven main geometrical parameters: inlet section height $a$ and width $b$, cylinder (barrel) height $h$, cyclone total height $H_{t}$, dust outlet diameter (cone tip diameter) $B_{c}$, gas outlet diameter (also, called vortex finder diameter) $D_{x}$ and vortex finder height $S$. All these parameters always given as a ratio of the cyclone body diameter $D$. It is generally known that these seven dimensions characterize the collection efficiency (cut-off diameter) and pressure drop of the cyclone separator [1-11].

\footnotetext{
${ }^{*} \mathrm{PhD}$ researcher, Department of Mechanical Engineering, Vrije Universiteit Brussel, Pleinlaan 2 -1050 Brussels- Belgium, /Email khairy.elsayed@vub.ac.be .

${ }^{\dagger}$ Professor, Department of Mechanical Engineering, Vrije Universiteit Brussel, Pleinlaan 2 1050 Brussels- Belgium, /Email khairy.elsayed@vub.ac.be .
} 
In cyclone separators, a strongly swirling turbulent flow is used to separate phases with different densities. The typical geometrical layout of a gas cyclone, used to separate particles from a gaseous stream, depicted in Fig. 1(a), corresponds to the Stairmand high-efficiency cyclone. The tangential inlet generates the swirling motion of the gas stream, which forces particles toward the outer wall where they spiral in the downward direction. Eventually the particles are collected in the dustbin (or flow out through a dipleg) located at the bottom of the conical section of the cyclone body. The cleaned gas leaves through the exit pipe at the top. Swirl and turbulence are the two competing phenomena in the separation process: the swirl induces a centrifugal force on the solids phase which is the driving force behind the separation; turbulence disperses the solid particles and enhances the probability that particles get caught in the exit stream. Both phenomena are related to the particle size, and the flow conditions in the cyclone [12].

While the cyclone geometry is simple, the flow is extremely complicated three-dimensional swirling flow. The complexity of the gas solid flow pattern in cyclones has long been a matter of many experimental and theoretical works. At present laser doppler anemometry (LDA) [e.g. 13, 14] and particle image velocimetry (PIV) [e.g. 15-17] are frequently employed to study experimentally the flow structure in the cyclones. As for the theoretical work, computational fluid dynamics (CFD) codes have proven to be a useful tool for simulating cyclonic flows [e.g. 1, 2, 12, 18-21]. The geometry of the cyclone affects the flow pattern and performance. A dustbin is attached to the dust outlet for conventional cyclones to collect the separated solid particles. Some experiments had indicated that much gas flow entered into the dustbin through here. However, because the bottom of the dustbin is stifled, the gas flow will return and re-enter into the separation space, which will disturb some separated particles and bring them into the inner core vortex, and lead to so-called "re-entrainment", thus will affect the separation efficiency of the cyclone [22].

Although many works have been carried out to investigate the influence of different geometric parameters such as cyclone length, inlet and outlet pipe geometries etc. on the performance of cyclones [e.g. 19, 23-26], there has been little work concerning the dust outlet geometries.

Obermair et al. [27] performed cyclone tests with five different dust outlet geometries to find the influence of the dust outlet geometry on the separation process. They showed that separation efficiency can be improved significantly by changing the dust outlet geometry, and they reported that further research is needed to clarify precise effects of dust outlet geometry. The effect of a dipleg (a vertical tube between the cyclone and the dustbin) was posed and investigated by several researchers [e.g. 28, 29].

The previous studies on the effect of dust outlet shape on the cyclonic flow can be classified into the following categories:

1. Comparison between cyclones with dustbin and that with (dustbin and dipleg) [e.g. 22, 27, 28]. Obermair et al. [27] investigated experimentally the effect of different dust outlet geometries on the flow pattern. But the given flow pattern was limited to the cyclone bottom. The effects of the dust outlet on the velocity profiles are not given.

2. Comparison between the cyclone with and without dipleg (prolonged cyclones). Kaya \& Karagoz [29] numerically investigated the flow characteristics and particle collection efficiencies of conventional and prolonged cyclones.

3. Comparison between cyclone with and without dustbin [e.g. 30]. Elsayed \& Lacor [30] numerically investigated two cyclones with and without dustbin. They reported a negligible effect of the dustbin on the performance. They reported further research is needed with the cyclone with dipleg and dust hopper. 
As these studies did not present enough information about the effect of the dust outlet shape on the flow pattern, velocity profiles and performance. Also there was no clear comparison between the four cases; separation space only (cylinder on cone), cyclone with cylindrical shape dustbin, and cyclone with vertical tube (dipleg). The present numerical investigation aims to examining the influence of dust outlet shape, on the numerically predicted flow pattern and the cyclone performance. This serves two purposes: (1) it demonstrates whether simulation of the flow taking into account only the separation space is sufficient (no need to include the dustbin or the dipleg). (2) It gives information for the designer about the effect of the configuration under the cyclone on the flow pattern and performance.

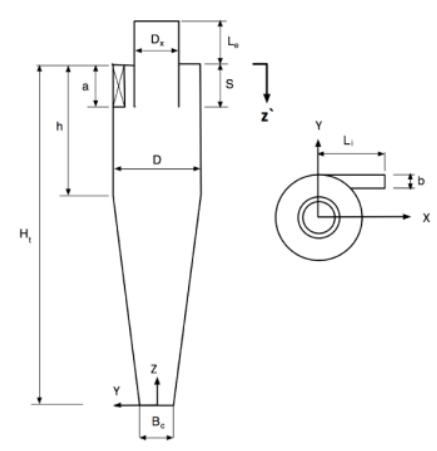

(a) Cyclone I

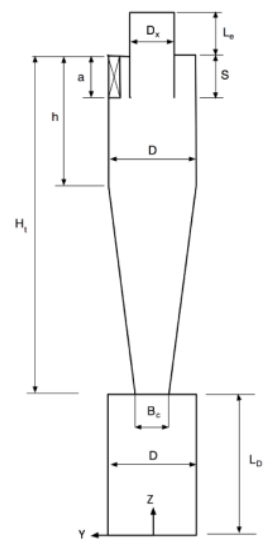

(b) Cyclone II

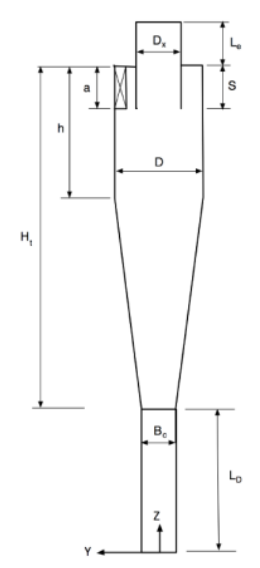

(c) Cyclone III

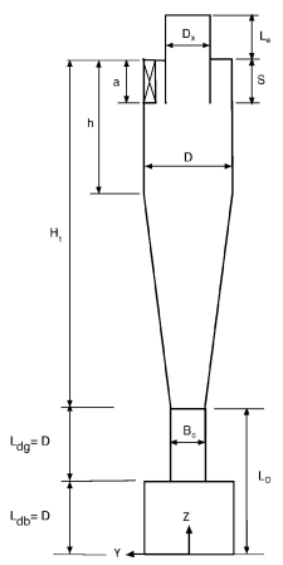

(d) Cyclone IV

Fig. 1: Schematic diagrams for the four tested cyclone separators

\section{Numerical Simulation}

\subsection{Configurations of the Tested Cyclones}

The numerical simulations were performed on four cyclones. Cyclone I has only the cylinder on cone shape (separation space only), cyclone II has a dustbin, cyclone III has a dipleg while cyclone IV has a dust hopper (dustbin plus dipleg). Figure 1 and Table 1 give the cyclones dimensions. Nine sections are used to plot the velocity profiles as shown in Table 2.

Table 1: The geometrical dimensions of the tested cyclones*

\begin{tabular}{lcc}
\hline Dimension & $\begin{array}{c}\text { Length } \\
(\mathrm{m})\end{array}$ & $\begin{array}{c}\text { Dimension ratio } \\
\text { (Dimension/D) }\end{array}$ \\
\hline Body diameter, $D$ & 0.205 & 1 \\
Inlet height, $a$ & 0.105 & 0.5 \\
Inlet width, $b$ & 0.041 & 0.2 \\
Gas outlet diameter, $D_{x}$ & 0.105 & 0.5 \\
Gas outlet duct length, $S$ & 0.105 & 0.5 \\
Cone tip-diameter, $B_{c}$ & 0.076875 & 0.375 \\
Cylinder height, $h$ & 0.3075 & 1.5 \\
Cyclone height, $H_{t}$ & 0.82 & 4 \\
\hline
\end{tabular}

* The outlet section is above the cyclone surface by $L_{e}=0.5 \mathrm{D}$. The inlet section located at a distance $L_{i}=0.75 \mathrm{D}$ from the cyclone center, the height of the dustbin and the dipleg, $L_{D}=2 \mathrm{D}$. 
Table 2: The position of different plotting sections*

\begin{tabular}{lccccccccc}
\hline \hline Section & S1 & S2 & S3 & S4 & S5 & S6 & S7 & S8 & S9 \\
\hline$z^{\prime} / D$ & 2.75 & 2.5 & 2.25 & 2 & 1.75 & 1.5 & 1.25 & 1.0 & 0.75 \\
\hline
\end{tabular}

$* z^{\prime}$ is measured from the top of the inlet section.

\subsection{Selection of the Turbulence Model}

For the turbulent flow in cyclones, the key to the success of CFD lies with the accurate description of the turbulent behavior of the flow [18]. To model the swirling turbulent flow in a cyclone separator, there are different turbulence models available in FLUENT. These range from the standard $k-\varepsilon$ model to the more complicated Reynolds stress turbulence model (RSM) and large eddy simulation (LES) methodology as an alternative for RANS models. The standard $k-\varepsilon$, RNG $k-\varepsilon$ and Realizable $k-\varepsilon$ models were not optimized for strongly swirling flows found in cyclones [31]. The Reynolds stress turbulence model (RSM) requires the solution of transport equations for each of the Reynolds stress components and yields an accurate prediction on swirl flow pattern, axial velocity, tangential velocity and pressure drop on cyclone simulation [32]. It will be used in this study to reveal the effect of dust outlet shape on the turbulent flow in the cyclone separator.

\subsection{Solver Settings}

The finite volume method has been used to discretize the partial differential equations of the model using the SIMPLEC (Semi-Implicit Method for Pressure-Linked EquationsConsistent) method for pressure velocity coupling and QUICK (Quadratic Upstream Interpolation for Convective Kinematics) scheme to interpolate the variables on the surface of the control volume. The implicit coupled solution algorithm was selected. The unsteady Reynolds stress turbulence model (RSM) was used in this study with a time step of 1E-4 s.

The air inlet velocity equals $20 \mathrm{~m} / \mathrm{s}$, corresponding to air inlet volume flow rate $Q_{\text {in }}$ of $0.08405 \mathrm{~m}^{3} / \mathrm{s}$, air density $1.225 \mathrm{~kg} / \mathrm{m}^{3}$ and dynamic viscosity of $178.940 \mathrm{E}-6 \mathrm{~Pa}$ s, leading to a Reynolds number of 2.672E4 based on the cyclone diameter and the area averaged inlet velocity. The turbulent intensity equals 5\% and characteristic length equals 0.07 times the inlet width [33]. Velocity inlet boundary condition is applied at inlet, outflow at gas outlet and wall boundary condition at all other boundaries.

Different grades of grid refinement were tested, with the first grid point located in various regions of the boundary layer. The grid refinement study shows that a total number of about 260230 hexahedral cells for cyclone I, 593125 hexahedral cells for cyclone II (with dustbin), 322286 hexahedral cells for cyclone III (with dipleg) and 441062 hexahedral cells for cyclone IV (with dustbin plus dipleg) are sufficient to obtain a grid-independent solution, and further mesh refinement yields only small, insignificant changes in the numerical solution. These simulations were performed on an 8 nodes CPU Opteron 64 Linux cluster using FLUENT commercial software.

\section{Validation of the Numerical Model}

\subsection{Comparison of Experimental and Simulation Velocities}

In order to validate the obtained results, it is necessary to compare the prediction with experimental data. The comparison performed with the measurements of Hoekstra [34] of the Stairmand cyclone using Laser doppler anemometry (LDA). The present simulation is compared with the measured axial and tangential velocity profiles at an axial station located at $94.25 \mathrm{~cm}$ from the cyclone bottom $\left(D_{x} / D=0.5\right)$ as shown in Fig. 2 (cf. Hoekstra [34] for more 
details about the used cyclone in this validation). The RSM simulation matches the experimental velocity profile with underestimation of the maximum tangential velocity, and overestimation of the axial velocity at the central region. Considering the complexity of the turbulent swirling flow in the cyclones, the agreement between the simulations and measurements is considered to be quite acceptable.
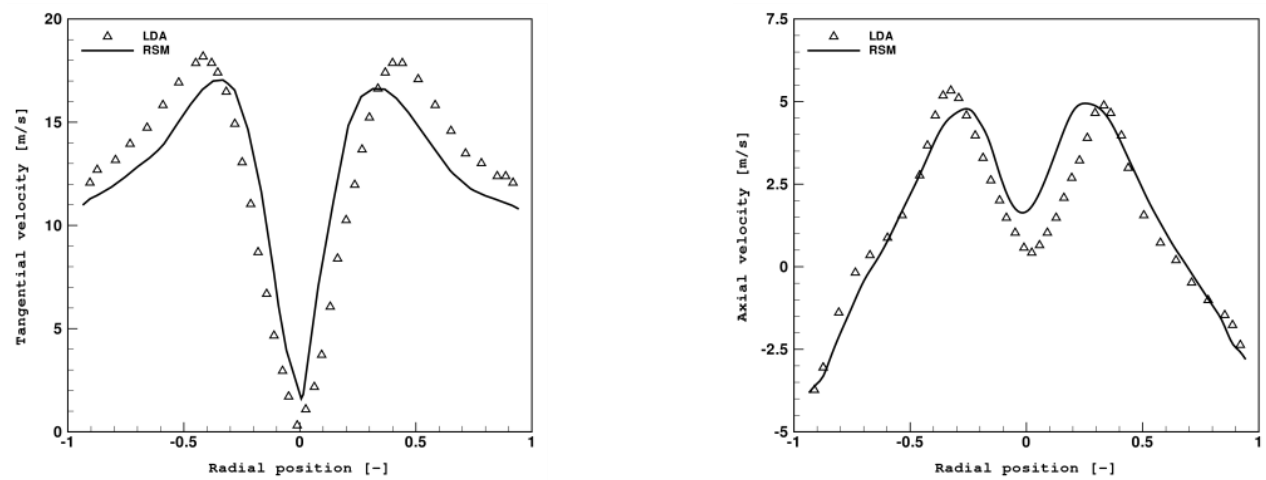

Fig. 2: Comparison of the time averaged tangential and axial velocity between the LDA measurements, Hoekstra [34] and the current Reynolds stress turbulence model (RSM) results at $94.25 \mathrm{~cm}$ from the cyclone bottom. From left to right tangential and axial velocity, $D_{x} / D=0.5$, the inlet velocity $=10 \mathrm{~m} / \mathrm{s}$.

\subsection{Comparison of experimental and simulation pressure drops and cut-off diameter}

The cyclone pressure drop is calculated as the pressure difference between the inlet and the average pressure across the vortex finder exit [34]. The experimental pressure drop of the cyclone can be calculated by the difference between the pressures at the inlet and outlet [35]. The estimation of the total pressure drop (static pressure plus dynamic pressure) is more accurate as it takes into consideration the change in the flow kinetic energy between the inlet and outlet sections. A comparison of the pressure drops (both, the static and total), the cut-off diameter (at particle density of $2740 \mathrm{~kg} / \mathrm{m}^{3}$ ) obtained from the experimental data [34], CFD prediction is shown in Table 3 . Table 3 indicates a very small deviation from the experimental values in both the calculated pressure drop and cut-off diameter. As the errors are less than $4 \%$, so it is in the same magnitude as the experimental error [35]. The above comparison results show that the numerical model employed in this study can be used to analyze the gas flow field and performance of the cyclone separator.

Table 3: Validation of the computational pressure drop and cut-off diameter

\begin{tabular}{lccc}
\hline \hline & Static pressure drop & Total pressure drop & Cut-off diameter \\
$\mathrm{N} / \mathrm{m}^{2}$ & $\mathrm{~N} / \mathrm{m}^{2}$ & $\mu \mathrm{m}$ \\
\hline Experimental [34] & 300 & 312.95 & 1 \\
CFD & 309 & 321.95 & 0.965 \\
\% error & 3 & 2.876 & 3.5 \\
\hline \hline
\end{tabular}




\section{Results and Discussion}

\subsection{The Variation of Flow Properties in the Axial Direction}

The tangential velocity is the dominant component of the gas flow in cyclones, which results in the centrifugal force for particle separation [36]. Also the development of the axial velocity profile in axial direction will be analyzed for the four cyclones.

Figures $3 \& 4$ present the radial profiles of the time-averaged tangential and axial velocity and static pressure at nine axial stations. As expected, the tangential velocity profiles exhibit the so-called Rankine vortex, which consists of two parts, an outer free vortex and an inner solid rotation in the center (Fig. 3). The tangential velocity distribution in the inner region is rather similar at different sections for the same cyclone. In the outer region, due to the sharp drop in velocity magnitude in the near wall region, the distribution is different but the maximum tangential velocity is similar for all sections. Generally, the tangential velocity distribution varies only slightly with axial positions for the same cyclone, which is also reported in other articles [e.g. 13, 36 -38]. This means that, if the tangential velocity increases at one section of the cyclone, it will increase at all other sections. The axial velocity profiles at nine different stations are shown in Fig. 3. Two types of axial velocity profiles are observed. Cyclone I, III \& IV show an inverted W profile. Only cyclone II (with dustbin) has an inverted V profile. The reason for the two different axial velocity profiles can be explained by the change in the flow field pattern caused by the dustbin.

The radial profiles of the time-averaged static pressure are given in Fig. 4 for the four cyclones. Like for the tangential velocity, the axial variations of static pressure are very small for the same cyclone. An exception is cyclone I which shows some variations in the central part. Figure 5 compares the static pressure profiles for the four cyclones at sections S7-S9 (located at the cylindrical part of the cyclone, which is the most effective part of the cyclone in the separation process, the location of the highest area average tangential velocity). The plots at sections S7-S9 are also representative for the other sections, as the axial variations in the flow variables are small. From the comparison between the radial profiles of the four cyclones, the minimum pressure at the cyclone center is almost the same for all cyclones. The static pressure radial profiles of cyclones I, III \& IV almost coincide. Cyclone II (with dustbin) depicts fewer gradients in the radial direction. It has the lowest maximum pressure value. Referring to Fig. 5, there is no difference between the radial pressure profiles at the three sections for the same cyclone.

\subsection{The Effect of Dust Outlet Geometry on the Velocity Profiles}

Figure 6 compares the tangential and axial velocity profiles at sections S7-S9. The variation of velocity profiles (both axial and tangential) from cyclone to cyclone is mainly located at the central region for both the tangential and axial velocity. Since the effect of the dust outlet geometry on the tangential velocity (centrifugal force) is minor, it is expected that the collection efficiency (cut-off diameter) of the four cyclones will be comparable. The axial velocity profiles change from inverted $\mathrm{W}$ with a deep dip at the center for cyclone I (cylinder on cone) to inverted W with a small central dip for cyclone III (dipleg) \& IV (dustbin plus dipleg). The axial velocity profile for cyclone II (dustbin) exhibits an inverted V. 


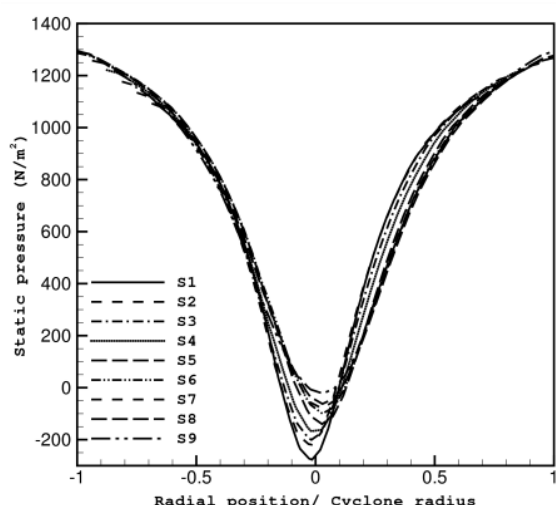

(a) Cyclone I

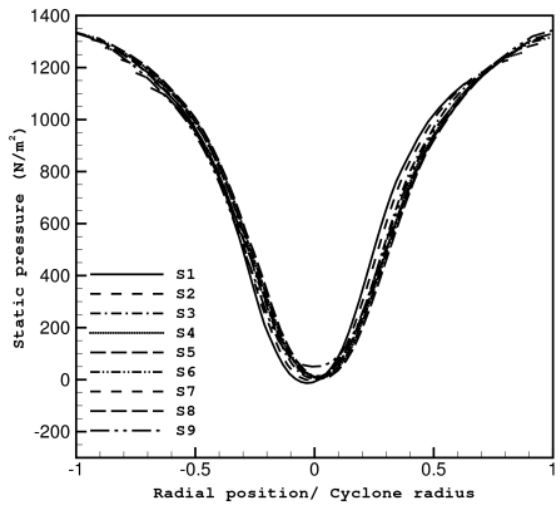

(c) Cyclone III (dipleg)

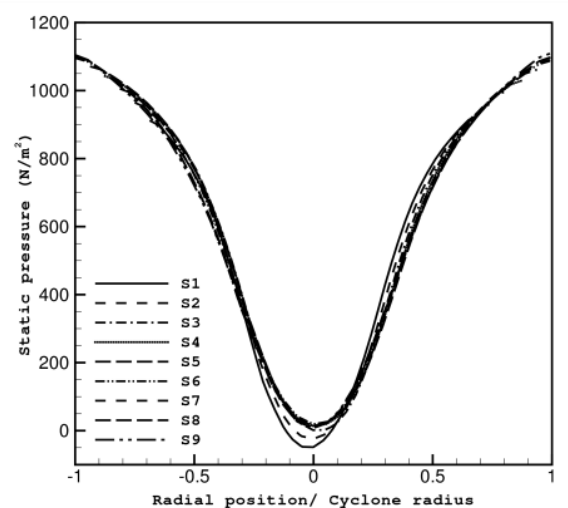

(b) Cyclone II (dustbin)

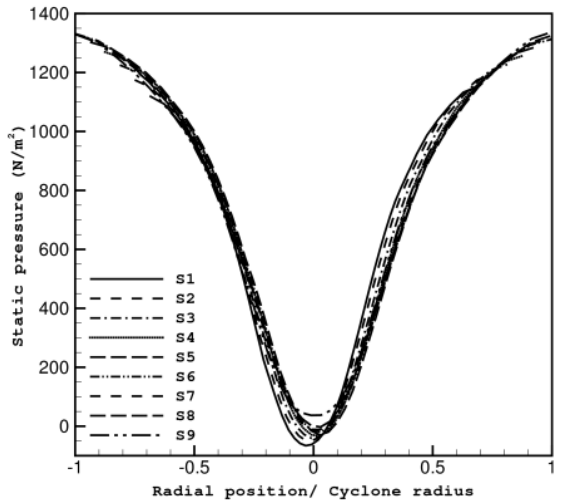

(d) Cyclone IV (dustbin plus dipleg)

Fig. 4: The radial profile for the time-averaged static pressure at different sections for the four cyclones.

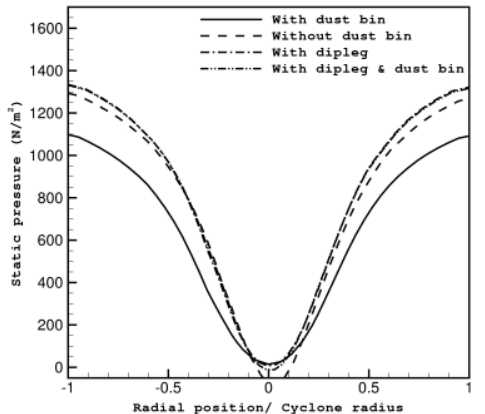

(a) The four cyclones at section $\mathrm{S} 7$

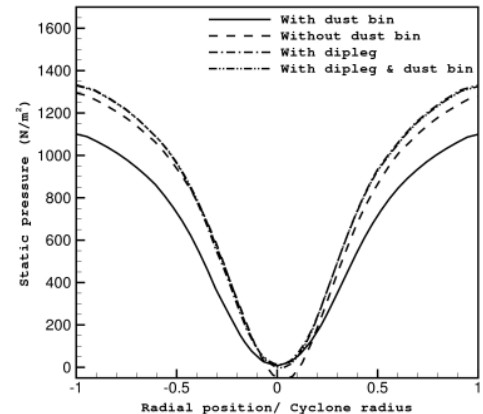

(b) The four cyclones at section S8

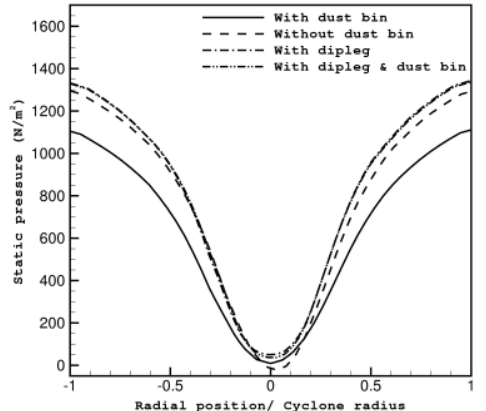

(c) The four cyclones at section $\mathrm{S} 9$

Fig. 5: The radial profile for the time-averaged static pressure at different sections for the four cyclones. 

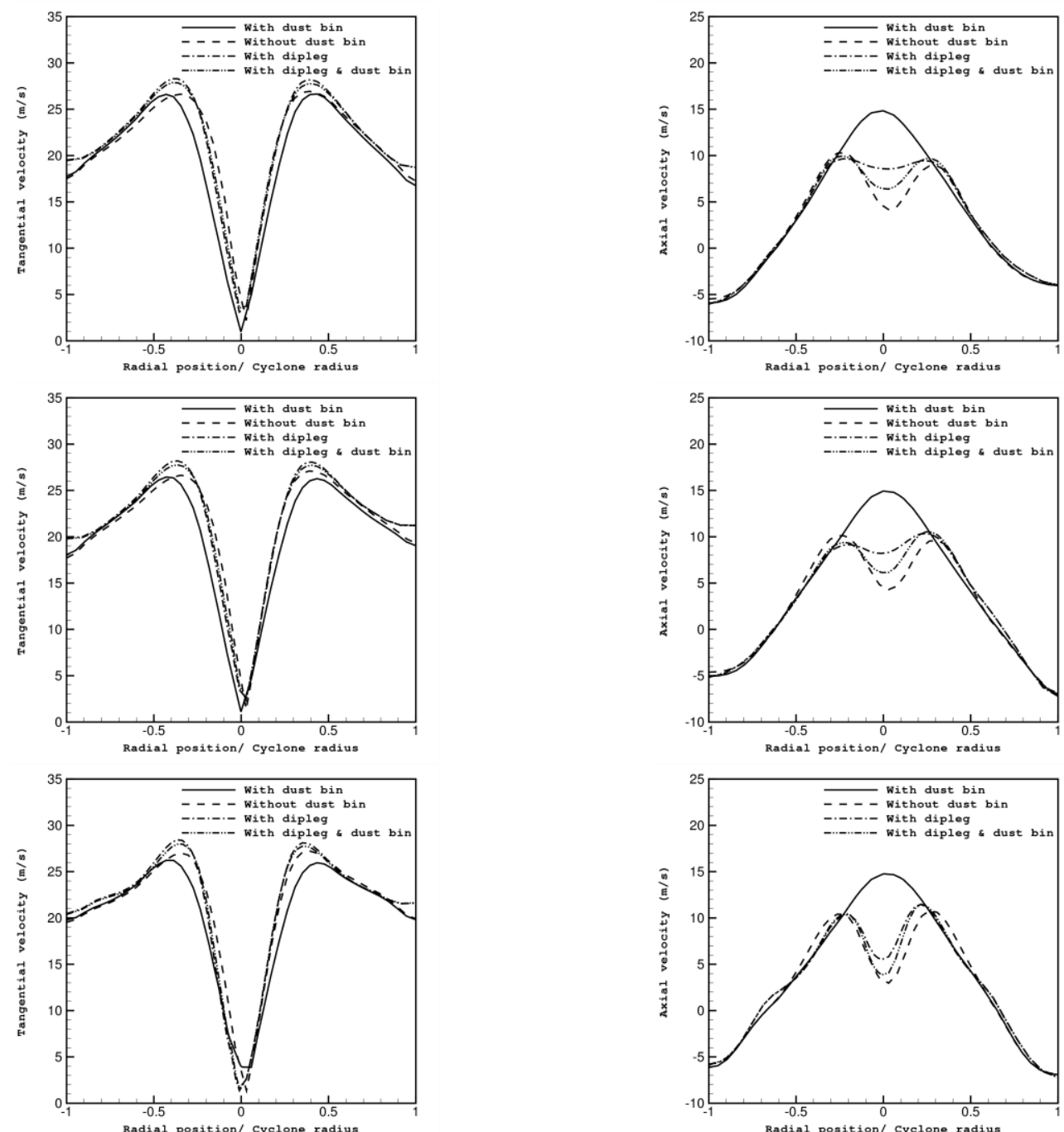

Fig. 6: The radial profile for the time averaged tangential and axial velocity at different sections on the $X-Z$ plane ( $Y=0$ ) at the inlet region (sections $S 7, S 8$ and S9). From top to bottom: section S7-S9. From left to right: tangential and axial velocity.

\subsection{Physical Interpretation of the Effect of Dust Outlet Geometry on the Flow Pattern}

The swirling motion of the gas generates a strong radial pressure gradient, the pressure being low in the centre of the vortex and high at the periphery (Fig. 4). As the strongly swirling gas enters the confines of the vortex finder on its way out of the cyclone, the swirl is attenuated through friction with the wall. This means that further up the vortex finder the pressure in the centre is higher than at the exit of the separation space: a reverse pressure gradient is present [28]. This drives an axial flow with dip in the centre of the vortex finder (inverted W profile), Figs. 3, 7 for cyclones I, III \& IV; this core flow prevails throughout the entire separation space of the cyclone in spite of the attenuation of swirl in the conical part of the cyclone.

With the dustbin included under the cyclone (cylinder on cone), a similar attenuation of swirl takes place in the dustbin driving an upwardly directed flow in this section and in turn in the cyclone. It turns out that this second driving force, presumably in combination with the attenuation of swirl in the conical section of the cyclone, causes the core flow to be upwardly directed throughout the cyclone separation space [28]. This explains the upwardly directed axial flow on the center (inverted V profile), Figs. 3, 7 for cyclone II. 
The static pressure $\left(\mathrm{N} / \mathrm{m}^{2}\right) \quad$ The tangential velocity $(\mathrm{m} / \mathrm{s}) \quad$ The axial velocity $(\mathrm{m} / \mathrm{s})$
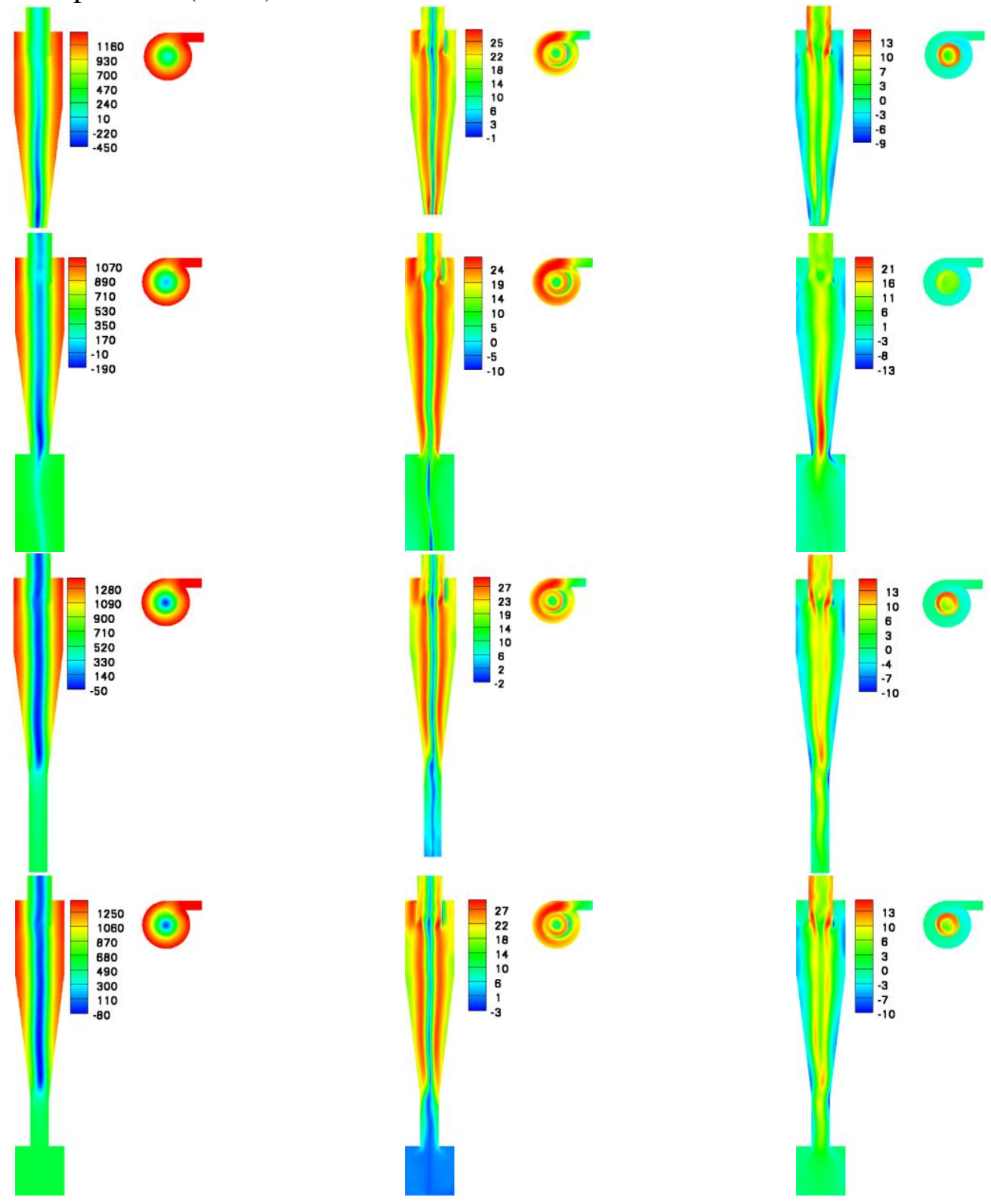

Fig. 7: The contour plots for the time averaged flow variables at sections $Y=0$ and throughout the inlet section. From left to right: the static pressure $\left(\mathrm{N} / \mathrm{m}^{2}\right)$, the tangential and the axial velocity $(\mathrm{m} / \mathrm{s})$.

\subsection{The Effect of Dust Outlet Geometry on the Performance}

In order to estimate the effect of dust outlet geometry on the performance parameters, the pressure drop and cut-off diameter have been calculated. Table 4 shows the effect of dust outlet geometry absence from the simulation domain on the pressure drop and cut-off diameter. From the comparison between the estimated pressure drop of cyclone I and the other three cyclones, the following comments are obtained. A slight underestimation is obtained when omitting the dipleg or dustbin plus dipleg from the simulation space. A slight overestimation results from omitting the dustbin. The pressure drop values given in Table 4 support the results obtained from the analysis of the static pressure contour plots. 
A discrete phase modeling (DPM) study has been performed by injecting $10^{4}$ particles from the inlet surface with a particle density of $860 \mathrm{~kg} / \mathrm{m}^{3}$ and with a particle size ranging from 0.025 till $5 \mu \mathrm{m}$. The effect of including the cyclone dustbin or dipleg, on the cut-off diameter (particle diameter of $50 \%$ collection efficiency) is also given in Table 4. Neglecting the effect of dust outlet geometry in the cyclone simulation slightly overestimates the cut-off diameter (when compare it with cyclone I).

Table 4: The effect of dust outlet geometry on the cyclone performance

\begin{tabular}{lcccc}
\hline Cyclone & I & II (dustbin) & III (dipleg) & IV (dustbin plus dipleg) \\
\hline Pressure drop $\left(\mathrm{N} / \mathrm{m}^{2}\right)$ & 960 & 890 & 1017 & 1008 \\
\hline Cut-off diameter $(\mu \mathrm{m})$ & 1.5 & 1.0 & 1.25 & 1.2 \\
\hline
\end{tabular}

\section{Conclusion and Future Work}

Four cyclones have been simulated using Reynolds stress model (RSM), to study the effect of the dust outlet geometry on the cyclone separator performance, flow pattern and velocity profiles. The following conclusions have been obtained.

- The maximum tangential velocity in the four cyclones is very similar.

- No acceleration occurs in the cyclone space (the maximum tangential velocity is nearly constant throughout the cyclone).

- The cyclone without dustbin slightly overestimates both the pressure drop and cut-off diameter. So the simulations with and without dustbin will produce nearly the same performance parameters.

- The cyclone without dipleg slightly underestimates the pressure drop and overestimates the cut-off diameter. So the simulations with and without dipleg will produce nearly the same performance parameters.

- The axial velocity patterns obtained by the four cyclones are different.

- If the main target of the CFD investigation is the performance parameters, one can safely simulate only the main separation space (cylinder on cone). However, if the aim is to investigate the flow field pattern, the dust outlet geometry should be included in the simulation domain.

As a recommendation for future work, this study is to be enlarged to include the following.

(1) The effect of dustbin \& dipleg shape, length, diameter, and interior details (like the inner cone at the dustbin inlet).

(2) The effect of air and dust flow rates, and particle properties.

(3) Perform the same study but using large eddy simulation (LES) to check the effect of dust outlet geometry on the vortex core precession.

\section{References}

[1] K. Elsayed, C. Lacor, Optimization of the cyclone separator geometry for minimum pressure drop using mathematical models and CFD simulations, Chemical Engineering Science 65 (22) (2010) 6048-6058.

[2] K. Elsayed, C. Lacor, The effect of cyclone inlet dimensions on the flow pattern and performance, Applied Mathematical Modelling 35 (4) (2011) 1952-1968. 
[3] B. Saltzman, J. Hochstrasser, Design and performance of miniature cyclone for respirable aerosol sampling, Environmental Science \& Technology 17 (7) (1983) 418424.

[4] J. Dirgo, D. Leith, Cyclone collection efficiency: Comparison of experimental results with theoretical predictions, Aerosol Science and Technology 4 (1985) 401-415.

[5] J. Dirgo, D. Leith, Performance of theoretically optimized cyclones, Filtration \& separation 22 (2) (1985) 119-125.

[6] D. L. Iozia, D. Leith, Effect of cyclone dimensions on gas flow pattern and collection efficiency, Aerosol Science and Technology 10 (3) (1989) 491-500.

[7] D. L. Iozia, D. Leith, The logistic function and cyclone fractional efficiency, Aerosol Science and Technology 12 (3) (1990) 598-606.

[8] G. Ramachandran, D. Leith, J. Dirgo, H. Feldman, Cyclone optimization based on a new empirical model for pressure drop, Aerosol Science and Technology 15 (1991) $135-148$.

[9] M. E. Moore, A. R. McFarland, Performance modeling of single-inlet aerosol sampling cyclones, Environmental Science and Technology 27 (9) (1993) 1842-1848.

[10] Y. Zhu, K. W. Lee, Experimental study on small cyclones operating at high flow rates., Journal of Aerosol Science 30 (1999) 1303-1315.

[11] R. Xiang, K. W. Lee, Exploratory study on cyclones of modified designs, Particulate Science and Technology 19 (4) (2001) 327-338.

[12] J. J. Derksen, S. Sundaresan, H. E. A. van den Akker, Simulation of mass-loading effects in gas-solid cyclone separators, Powder Technology 163 (2006) 59-68.

[13] G. Solero, A. Coghe, Experimental fluid dynamic characterization of a cyclone chamber, Experimental Thermal and Fluid Science 27 (2002) 87-96.

[14] L. Y. Hu, L. X. Zhou, J. Zhang, M. X. Shi, Studies on strongly swirling flows in the full space of a volute cyclone separator, AIChE Journal 51 (3) (2005) 740-749.

[15] P. A. Yazdabadi, A. J. Grifflths, N. Syred, Characterization of the PVC phenomena in the exhaust of a cyclone dust separator, Experiments in Fluids 17 (1994) 84-95.

[16] T. O’Doherty, A. J. Griffiths, N. Syred, P. J. Bowen, W. Fick, Experimental analysis of rotating instabilities in swirling and cyclonic flows, Developments in Chemical Engineering and Mineral Processing 7 (1999) 245-267.

[17] B. Zhang, S. Hui, Numerical simulation and PIV study of the turbulent flow in a cyclonic separator, in: International Conference on Power Engineering, Hangzhou, China, 2007.

[18] W.D. Griffiths, F. Boysan, Computational fluid dynamics (CFD) and empirical modelling of the performance of a number of cyclone samplers, Journal of Aerosol Science 27 (2) (1996) 281-304.

[19] J. Gimbun, T. G. Chuah, T.S. Y. Choong, A. Fakhru'l-Razi, A CFD study on the prediction of cyclone collection efficiency, International Journal for Computational Methods in Engineering Science and Mechanics 6 (3) (2005) $161-168$.

[20] J. Gimbun, T. Chuah, A. Fakhru'l-Razi, T. S. Y. Choong, The influence of temperature and inlet velocity on cyclone pressure drop: a CFD study, Chemical Engineering \& Processing 44 (1) (2005) 7-12.

[21] B. Zhao, Y. Su, J. Zhang, Simulation of gas flow pattern and separation efficiency in cyclone with conventional single and spiral double inlet configuration, Chemical Engineering Research and Design 84 (2006) 1158-1165.

[22] F. Qian, J. Zhang, M. Zhang, Effects of the prolonged vertical tube on the separation performance of a cyclone, Journal of Hazardous Materials B (136) (2006) 822-829.

[23] F. Boysan, B. C. R. Ewan, J. Swithenbank, W. H. Ayers, Experimental and theoretical studies of cyclone separator aerodynamics, IChemE Symp Series 69 (1983) 305 - 320. 
[24] R. Xiang, S. H. Park, K. W. Lee, Effects of cone dimension on cyclone performance., Journal of Aerosol Science 32 (4) (2001) 549-561.

[25] K. S. Lim, H. S. Kim, K. W. Lee, Characteristics of the collection efficiency for a cyclone with different vortex finder shapes, Journal of Aerosol Science 35 (6) (2004) 743-754.

[26] A. Raoufi, M. Shams, M. Farzaneh, R. Ebrahimi, Numerical simulation and optimization of fluid flow in cyclone vortex finder, Chemical Engineering and Processing 47 (2008) 128-137.

[27] S. Obermair, J. Woisetschlager, G. Staudinger, Investigation of the flow pattern in different dust outlet geometries of a gas cyclone by laser doppler anemometry, Powder Technology 138 (2003) 239-251.

[28] A. Hoffmann, M. De Groot, A. Hospers, The effect of the dust collection system on the flow pattern and separation efficiency of a gas cyclone, The Canadian Journal of Chemical Engineering 74 (1996) 464-470.

[29] F. Kaya, I. Karagoz, Numerical investigation of performance characteristics of a cyclone prolonged with a dipleg, Chemical Engineering Journal 151 (2009) 39-45.

[30] K. Elsayed, C. Lacor, The effect of cyclone dustbin on the flow pattern and performance, in: Tenth International Congress of Fluid Dynamics (ICFD10), ASME, Egypt, ICFD10-EG-3092, 2010, Ain Soukhna, Red Sea, Egypt, 2010.

[31] T. Chuah, J. Gimbun, T. S. Choong, A CFD study of the effect of cone dimensions on sampling aerocyclones performance and hydrodynamics, Powder Technology 162 (2006) $126-132$.

[32] M. D. Slack, R. O. Prasad, A. Bakker, F. Boysan, Advances in cyclone modeling using unstructured grids, Trans IChemE. 78 Part A, (2000).

[33] A. J. Hoekstra, J. J. Derksen, H. E. A. Van Den Akker, An experimental and numerical study of turbulent swirling flow in gas cyclones, Chemical Engineering Science 54 (1999) 2055-2065.

[34] A. J. Hoekstra, Gas flow field and collection efficiency of cyclone separators, Ph.D. thesis, Technical University Delft (2000).

[35] F. Qian, M. Zhang, Effects of the inlet section angle on the flow field of a cyclone, Chemical Engineering \& Technology 30 (11) (2007) 1521-4125.

[36] R. B. Xiang, K. W. Lee, Numerical study of flow field in cyclones of different height, Chemical Engineering and Processing 44 (2005) 877-883.

[37] A. Gorton-Hülgerth, J. Woisetschläger, G. Wigley, G. Staudinger, Investigation of the flow field in the upper part of a cyclone with laser and phase doppler anemometry, Particle \& Particle Systems Characterization 17 (2000) 21-27.

[38] W. Peng, A. C. Hoffmann, P. J. A. J. Boot, A. Udding, H. Dries, A. Ekker, J. Kater, Flow pattern in reverse-flow centrifugal separators, Powder Technology 127 (2002) 212 -222 . 